SWIFT PETROLOGICAL MICROSCOPE. Triplecentring Nosepiece. Iris Diaphragm. Condenser. Camera Lucida \&c. 1951 Model. Unused. Cost $£ 70$ 10s. Accept 55 gns.-Lowe, 2 Stuart Ave., London, W. 5.

WANTED. Geological Magazine, Vol. 83, No. 1 (or complete volume). Geology Department, University of Otago, Dunedin,

New Zealand.

\title{
OUTLINES OF STRUCTURAL GEOLOGY
}

by

E. SHERBON HILLS

Professor of Geology and Mineralogy in the University of Melbourne

This new edition reviews the important new researches into many branches of structural geology. Large sections of the book have been completely revised.

3rd edition, revised and reset

With 4 plates and 107 diagrams

I2s. 6d.

\section{METHUEN}

